\title{
Does Anger Expression Mediate the Relationship Between Parental Rejection and Direct and Indirect Forms of Non-suicidal Self-injury?
}

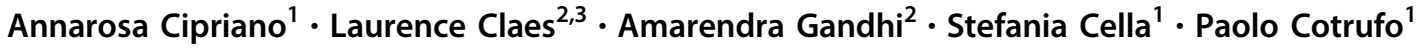

Accepted: 30 September 2020 / Published online: 15 October 2020

(c) The Author(s) 2020

\begin{abstract}
Non-suicidal self-injury (NSSI) is defined as the intentional destruction of one's own body without an intent to die (e.g., selfcutting). On the other hand, indirect forms of self-injury refer to behaviors in which people harm themselves in an indirect way (e.g., substance use). Existing literature suggests that a negative parent-child relationship may increase vulnerability to NSSI and indirect forms of self-injury. However, little is known about the potential mediators that intervene in the aforementioned relationship. Therefore, the present work tests a path model to investigate whether the manner of anger expression-anger-in (redirect anger inwardly) or anger-out (express anger outwardly)—mediates the association between parental rejection and direct (specifically self-cutting) and indirect (specifically substance use) forms of self-injury in a crosssectional sample of Italian adolescents. We assessed self-injury, parental acceptance/rejection, and the expression of anger using self-report questionnaires in 2464 high school students, aged $13-20$ years $\left(M_{\text {age }}=15.93, \mathrm{SD}=1.49\right)$. Additionally, characteristics of NSSI were also assessed using semi-structured interviews. We found that parental rejection was significantly positively associated with both self-cutting and substance use. The aforementioned relationship was mediated through anger-in for self-cutting, and through anger-out for substance use. The current work demonstrated that anger expression might work as a bridge between invalidating caregiving environment (i.e., rejecting), in which an individual feels unloved and uncared for, and the occurrence of self-cutting and substance use. The salient role of anger management in the development of prevention and intervention programs for NSSI and indirect self-injury among adolescents is discussed.
\end{abstract}

Keywords Non-suicidal self-injury $\cdot$ Indirect self-injury $\cdot$ Parental rejection $\cdot$ Anger expression $\cdot$ Self-cutting $\cdot$ Substance use

\section{Highlights}

- Parental rejection increased the likelihood of engaging in self-cutting and substance use.

- Express anger inwardly mediates the pathway from parental rejection to self-cutting.

- Express anger outwardly mediates the pathway from parental rejection to substance use.

Non-suicidal self-injury (NSSI) refers to the socially unacceptable and intentional destruction of one's own body tissue in the absence of suicidal intent (Favazza 1996).

Paolo Cotrufo

paolo.cotrufo@unicampania.it

1 Observatory on Eating Disorders, University of Campania "Luigi Vanvitelli”, Caserta, Italy

2 Faculty of Psychology and Educational Sciences, KU Leuven, Leuven, Belgium

3 Faculty of Medicine and Health Sciences, University of Antwerp, Antwerp, Belgium
Culturally sanctioned practices, such as tattoos and piercings, are not considered as NSSI (Claes et al. 2005). In contrast to NSSI - which is often considered as direct form of self-injury, indirect forms of self-injury refer to behaviors such as substance use, dysfunctional eating behaviors (e.g., starvation, vomiting, purging), engaging in reckless behaviors (e.g., risky sexual practices), in which people harm themselves in an indirect way (e.g., alcohol abuse can cause liver cirrhosis; Claes et al. 2003; St. Germain and Hooley 2012). In the present study, we focused on selfcutting as a direct form of NSSI; whereas substance (ab)use - a major medical and public health concern often initiated in adolescence (Schulte and Hser 2013)—as indirect form of self-injury. 
NSSI is a highly prevalent behavior in adolescence. Large reviews and meta-analytical studies indicate that the lifetime prevalence rates of NSSI is estimated to be around $18 \%$ within community samples of adolescents (Muehlenkamp et al. 2012; Swannell et al. 2014). Using a survival analysis approach, Gandhi et al. (2018) have demonstrated that NSSI has the highest odds of initiating during adolescence. A recent study by Victor and Klonsky (2018) has found that about $20 \%$ of adolescents engaged in NSSI, and the most endorsed behavior was self-cutting. A large body of research has suggested that females are more likely than males to engage in NSSI (Bresin and Schoenleber 2015). Although NSSI has shown high comorbidity with other mental disorders, such as depression and anxiety (Kiekens et al. 2018), NSSI can also be highly disabling in its own right, as it causes greater distress and impairment (Zetterqvist 2017).

Like NSSI, substance use is also a widespread phenomenon among adolescents (Moss et al. 2014), which is linked with adverse short- and long-term consequences, such as addiction and abuse in adulthood (RichmondRakerd et al. 2017). Although NSSI and indirect forms of self-injury may be associated with each other, available literature suggests that individuals who engage in NSSI may differ from those who engage in indirect forms of selfinjurious behaviors, as the direct NSSI group reported a higher level of self-criticism and suicide risk (St. Germain and Hooley 2012). According to the existing literature on NSSI and indirect forms of self-injury, family characteristics can play an important role in increasing the vulnerability to self-injury (Baetens et al. 2015; Baetens et al. 2014; Cella et al. 2014; Johnson et al. 2014). Low parental support and care, and high parental neglect have been identified as risk factors for NSSI (Bureau et al. 2010; Claes et al. 2004) and substance use (Rusby et al. 2018). Careless, non-protective, and invalidating caregiving relationships have been shown to be associated with the occurrence, frequency and severity of NSSI among adolescents (Baetens et al. 2014; Bureau et al. 2010; Martin et al. 2016). Likewise, a combination of poor parent-child relationship quality and high parental control predicted the risk of engaging in alcohol use, binge drinking, and cannabis initiation, during the transition from early to midadolescence (Rusby et al. 2018). Finally, neglectful and harsh parenting was significantly positively associated with alcohol and drug use (Adalbjarnardottir and Hafsteinsson 2003; Alati et al. 2014).

Intuitively, such invalidating parent-child relationships are likely to be marked by parental rejection. Consistent with Rohner's (1986) conceptualization, parental rejection refers to one end of a bipolar continuum that represents the quality of the emotional and behavioral bond between parents and offspring (i.e., warmth/rejection). The rejection end is marked by the absence or withdrawal of parental love, care, acceptance, and support, and by the presence of a series of hurtful behaviors and emotions (i.e., criticism, aggression). Rejecting parents are more prone to criticize, neglect, and disapprove their children (Rohner et al. 2005). Although parental rejection has been regarded as a strong predictor of psychological maladjustment (Rohner and Brothers 1999), to date, only few studies have examined the relation between parental rejection and self-harming behaviors. Quirk et al. (2015) for example, reported that parental rejection has an indirect effect on NSSI through maladaptive self-schemas and motivations to engage in NSSI. Similarly, Latina and Stattin (2016) demonstrated that parents' hostility-including coldness/rejection-is positively associated with NSSI. Also, parental rejection has been found to predict the intent to use substances and substance abuse (Rohner and Britner 2002; Teichman and Kefir 2000). Although these pioneer studies provide empirical support linking parental rejection to self-injurious behaviors, future research is needed to explore its role in selfinjury occurrence and the intervening mechanisms.

There is evidence showing that parental rejection promotes anger dysregulation (Dickson et al. 2019), impairing how offspring express their angry feelings (Kerr and Schneider 2008). Expression of anger can occur in two forms: (a) anger-in refers to the suppression of angry feelings, redirecting them inwardly, (b) anger-out refers to the expression of anger outward, toward people or things within the environment (Spielberger et al. 2014). A study by Clark et al. (2002) explored the association between parental acceptance and anger-in and to anger-out, but they failed to observe any association between the two concepts. Given the paucity of studies and the contradictory findings, further research exploring the association between parental rejection and expression of anger is urgently needed.

Emotion regulation vulnerabilities have been regarded as the roots of maladaptive defenses to cope with intense affects, such as anger (Khantzian 1997). Also, the two-stage model of outward and inward-directed aggression (Apter et al. 1993) has suggested that suicidal behaviors, including self-injury, may be an expression of an aggressive impulse. In this respect, one potential explanation for the association between parental rejection and self-injury may be that parental rejection may contribute to a dysregulated anger expression that, in turn, may lead adolescents to express their anger toward themselves (Klonsky 2007). Accordingly, negative emotions, like anger, have been shown to trigger both NSSI and substance use (Cipriano et al. 2017; Eftekhari et al. 2004; Nichols et al. 2008). For instance, adolescent outpatients who engage in NSSI reported significantly higher levels of internalized anger compared to a control group (García-Nieto et al. 2015). Additionally, both alcohol and marijuana use were related to anger-out within 
adolescents who are in conflict with the law (Eftekhari et al. 2004). Likewise, anger expressed outwardly was found to be associated with addiction severity (Avci et al. 2017). Also, Khantzian (1997) posited that substance use "medicates" the inability to express (angry) feelings adaptively. These findings seem to suggest that those who engage in NSSI show higher levels of anger-in; whereas those who engage in indirect forms of self-injury direct their anger outwardly. However, these findings are not systematically replicated in other studies. Guertin et al. (2001), for example, showed that patients who attempted suicide by overdose and also engaged in NSSI reported higher levels of anger-out compared to those without NSSI.

Although anger was found to be strongly associated to parental rejection and both NSSI and indirect forms of self-injury (Claes et al. 2010; Eftekhari et al. 2004), no study has explored the role of anger expression as a mediating factor between parental rejection and (in)direct forms of self-injury. In the present study, we examined the prevalence and characteristics of NSSI and substance (ab) use in a large community sample of Italian adolescents, and we investigated whether the relationship between parental rejection and NSSI and substance (ab)use may be mediated by inwardly or outwardly directed anger. To fill this gap, we tested a path model to explore mediational pathways between parental rejection and (in)direct selfinjury through anger expression. In line with the literature presented above, parental rejection may affect the way in which adolescents express their anger, which, in turn, may lead to engaging in (in)direct self-injurious behaviors. More specifically, this research was guided by two main hypotheses: (a) anger-in mediates the relationship between parental rejection and NSSI (i.e., self-cutting); and (b) anger-out mediates the relationship between parental rejection and indirect forms of self-injury (i.e., substance use).

\section{Methods}

\section{Participants and Procedure}

\section{Participants}

A total of 3926 students from eleven public high schools located in Southern Italy were invited to participate in the study during the school year 2018-2019. A total of 2850 informed consent forms were returned. Fifty-two students were excluded because parents did not provide their informed consent. An additional 271 were absent or were engaged in other school activities during data collection, and 63 students were excluded due to the incompleteness of their response (response rate $=67.30 \%$ ). The final sample consisted of 2464 students-of whom $1585(64.3 \%)$ were females. On an average, 223 students $(\mathrm{SD}=55.01$; range $=$ 156-307) participated from each school. Further, on average, around 16.42 ( $\mathrm{SD}=5.09$; range 4-31) students were recruited from each class. Note that the nested structure in the sample (participants nested in school) was ignored as the interclass correlations among the study variables were generally very small (ranging from -0.0011 to 0.0305 ). The sample was representative of the Italian population regarding gender distribution, educational level, and marital status (ISTAT 2019b, 2019a; MIUR 2017). The mean age of the sample was $15.93(\mathrm{SD}=1.49$, range $=13-20$ years $)$, and $98.2 \%$ reported to have Italian nationality. The majority of students $(n=2390,97 \%)$ had both father and mother alive. In terms of family structure, $85.3 \%$ of participants lived within intact families, while $10.2 \%$ had separated or divorced parents. About $53.2 \%(n=1292)$ of the sample belonged to the upper-middle class, with about $60 \%$ of parents held diploma or degree.

\section{Procedure}

After school headmasters agreed to participate in our study, informed consent forms for parents were distributed via students in the weeks preceding the test administration. The questionnaires were filled out during school hours under the supervision of research assistants. Participation in the study was explained to be voluntary and anonymous. A unique alphanumeric code was assigned to each student in order to maintain confidentiality. Furthermore, information regarding available counseling services was provided to all participants. The study was performed in accordance with the ethical standards of the Helsinki declaration (World Medical Association, 2013), and it was approved by the Ethics Board of the Department of Psychology, University of Campania "Luigi Vanvitelli".

\section{Measures}

\section{Sociodemographic information}

Participants were asked questions regarding age, gender, family composition, and parents' educational level.

\section{Screening schedule}

Regular use of substances (i.e., at least twice a week) was assessed with a single-item question (yes/no) which, if endorsed positively, was followed up by a checklist of substances (e.g., alcohol, cannabis). Participants were also asked if they had ever engaged in NSSI ("Sometimes I purposefully injure myself"). Given the hidden nature of NSSI and the significant shame associated with it, we 
assessed NSSI behaviors by means of a semi-structured interview. As substance use among adolescents is far more socially acceptable than NSSI, candidates were not interviewed about this behavior.

\section{Non-suicidal self-injury}

The Deliberate Self-harm Inventory (DSHI; Gratz 2001) was administered as a semi-structured interview. The DSHI assesses NSSI characteristics. Each participant was asked whether they engaged in a specific NSSI behavior (i.e., cutting, burning, scratching) without suicidal intent. If positively endorsed, additional items assessed age of onset, frequency, duration, and severity of the NSSI behavior were also assessed. A preliminary data screening revealed that the prevalence of cutting was almost as high as the total rate of NSSI. A possible explanation for this finding is that in the first assessment phase (i.e., screening item) a checklist of NSSI behaviors was not provided. As cutting is the most well-known type of NSSI, it could have contributed to a misunderstanding and affect the true prevalence of NSSI within our sample. To tackle this assessment bias, we decided to include only cutting behaviors in further analysis. The DSHI has been translated and validated in Italian context, demonstrating adequate internal consistency and good convergent and discriminant validity (Cerutti et al. 2012).

\section{Parent acceptance/rejection}

To assess parenting style, we used the Parental Acceptance-Rejection Questionnaire-Short Form, Adolescent Version (PARQ-SF; Rohner 2005). The short version of the questionnaire consists of two identical forms (mother/father) of 24 items that are to be rated on a 4-point Likert scale ranging from "Almost always true" (4) to "Almost never true" (1). The total score of perceived parental acceptance/rejection is achieved by summing the following subscales: warmth and affection ("Lets me know she/he loves me"), hostility and aggression ("Yells at me when she/he is angry"), indifference and neglect ("She/He pays no attention to me as long as I do nothing to bother her/him"), and undifferentiated rejection ("She/He does not really love me"). Higher scores on the total scale represent high perceived parental rejection (mother/father). In the present study, a single measure of parental acceptance-rejection was obtained by summing the total scale score of each parent (Senese et al. 2017). The Italian adaptation demonstrated sound psychometric properties (Comunian 2002). In our study, the Cronbach's alpha coefficients for the parental acceptance-rejection scale were 0.91 for mother, 0.94 for father, and 0.95 for the total scale (mother + father).
Anger

The expression of anger was assessed by means the subscales of anger-in ("I keep things in") and anger-out ("I lose my temper") of the State-Trait Anger Expression Inventory (STAXI, Spielberger 1988). Each subscale consists of 8 items (i.e., "I keep things in" for anger-in; "I lose my temper" for anger-out) that are rated on a 4-point scale ranging from "Almost Never" (1) to "Almost Always" (4). All of the STAXI subscales have demonstrated adequate validity properties and good reliability with reported alpha coefficients ranging from 0.73 to 0.93 (Fuqua et al., 1991)). The STAXI has been translated and validated in Italian, and it has showed adequate internal consistency and validity (Comunian 1992). In our study, the Cronbach's alpha coefficients of the anger-in and the anger-out subscales were found to be 0.75 and 0.74 , respectively.

\section{Analytical Strategy}

Descriptive statistics were calculated by using SPSS $24^{\oplus}$ (IBM ${ }^{\oplus}$ Corp. 2016). To investigate associations between categorical variables, a Chi-Square test statistic was calculated, whereas Pearson's $r$ was calculated to investigate associations between interval-scaled variables. Given that item-level missingness of $1 \%$ in our data was far less than the 5\% cut-off suggested by Jakobsen et al. (2017), we expected our analysis to be unaffected by missing data. Moreover, baseline characteristics were not significantly different across those with and without missing values. Consequently, we used listwise deletion to handle missing data. The path model which we tested is shown in Fig. 1. Perceived parental rejection was introduced as exogenous variable, self-cutting and substance use were treated as endogenous variables, and anger-in and anger-out were introduced as the mediators. Age and gender were introduced in the model as covariates by regressing all the variables of interest on them. Our path model had following indirect effects: from parental rejection to self-cutting through anger-in, from parental rejection to

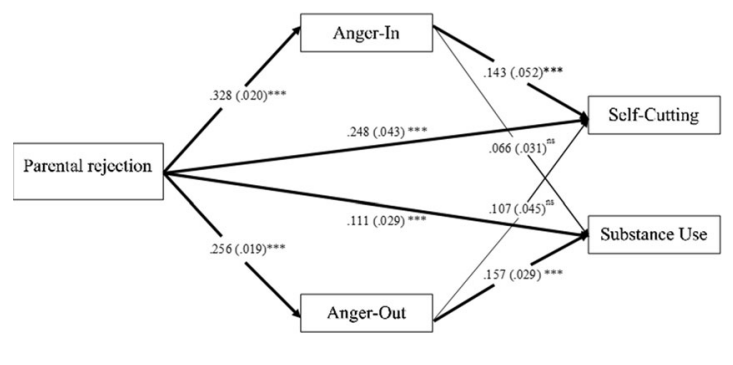

****p $<0.001$

Fig. 1 Path analysis model with standardized path coefficients and standard errors 
Table 1 Means, standard deviations, correlations, and alpha coefficients of cutting, substance use, parental rejection, anger-in, and anger-out

\begin{tabular}{lcccccccc}
\hline & M & SD & 1 & 2 & 3 & 4 & 5 & $\alpha$ \\
\hline 1. Cutting & - & - & - & -0.023 & $0.200^{* *}$ & $0.144^{* *}$ & $0.109^{* *}$ & - \\
2. Substance use & - & - & & & $0.144^{* *}$ & $0.122^{* *}$ & $0.161^{* *}$ & - \\
3. Parental rejection & 78.42 & 22.83 & & & & $0.339 * *$ & $0.263 * *$ & 0.95 \\
4. Anger-in & 18.74 & 5.58 & & & & $0.270^{* *}$ & 0.75 \\
5. Anger-out & 16.46 & 4.65 & & & & - & 0.74 \\
**p<0.01 & & & & & & &
\end{tabular}

self-cutting through anger-out, parental rejection to substance use through anger-in, parental rejection to substance use through anger-out. The significance of the indirect effects was tested by constructing $95 \%$ bias-corrected bootstrap confidence intervals (5000 draws) around the product terms. Model estimation was carried out using the weighted least squares means and variance adjusted (WLSMV) procedure as the outcome variables were dichotomous. Consistent with suggestions of Hoyle and Panter (1995), both absolute and incremental fit indices were taken into account to evaluating the individual models fit: (a) $\chi^{2}$ test-which should not be statistically significant (Hair et al. 1998), (b) the Root Mean Square Error of Approximation (RMSEA), (c) the Comparative Fit Index (CFI), (d) the Tucker-Lewis index (TLI). Acceptable fit indices were defined as follows: RMSEA $\leq 0.08$ (Brown and Cudeck 1993); CFI and TLI $\geq 0.90$ (Hoyle 2012). As the Chi-square statistic is sensitive to sample size, it was only used as a rough indicator of model fit. The path analysis was performed using Mplus (v7.4, Muthén and Muthén 2012).

\section{Results}

\section{Descriptive Characteristics of NSSI and Indirect Forms of Self-injury}

After screening, all students who positively endorsed the item "Sometimes I purposefully injure myself" ( $n=178$, $7.22 \%)$ and those who did not respond to this item $(n=15$, $0.60 \%$ ) were interviewed. The interview served to ensure the validity of our assessment procedure and clarify whether the self-injurious behaviors were interpreted by the adolescents in the same way as the researchers intended. After the interview, $5.03 \%(n=124$, female $=100$, males $=24)$ of students reported engaging in at least one episode of selfcutting. No significant gender $\left(\chi_{(1)}^{2}=17.577, p<0.001\right.$; $\Phi=0.085)$ and age differences $\left(t_{(2446)}=1.41, p=0.158\right.$; $d=0.13$ ) emerged between adolescents with and without self-cutting. The mean age of onset for self-cutting was 12.85 years $(\mathrm{SD}=1.46$, range $=9-18)$, and the average duration of the behavior was 20.05 months $(\mathrm{SD}=$
17.35 months; range $=1$ day to 72 months). Five student reported a frequency of more 3000 cuts, these frequency may reflect the actual frequency of cutting behaviors of the participants, and hence the values were still retained. The mean lifetime frequency of self-cutting was 518.06 (SD = 947.46, range $=1-3800$ ), whereas $5 \%$ trimmed mean was 383.81. Last episodes happened roughly 16 months before ( $\mathrm{SD}=16.73$ months; range 1 day to 82 months), with twelve students engaging in self-cutting in the period between 1 day and 3 weeks before the interview. No one reported seeking medical treatment after self-cutting.

Out of the total sample, $431(17.5 \%)$ adolescents reported regularly substance use $(15.05 \%$ alcohol, and $6.69 \%$ cannabis). Rate of substance use was higher among males than females $\left(\chi_{(1)}^{2}=15.459, p<0.001 ; \Phi=0.11\right)$. With respect to age, substance users were significantly older than non-users $\left(t_{(727.3)}=-11.888, p<0.001 ; d=0.58\right)$.

The descriptive statistics of the other study variables (parental acceptance/rejection, anger-in, and anger-out) and results of the bivariate correlations can be found in Table 1 . All variables were significantly and positively associated in the expected direction, with correlations ranging from $r=0.11$ to $r=0.33$, except for self-cutting and substance use $(r=-0.023, \mathrm{~ns})$.

\section{Path Analysis Model}

Given the absence of degree of freedom $(d f=0)$, the goodness-of-fit was perfect to the data $\left(\chi_{(0)}^{2}=0.000\right.$; $\mathrm{CFI}=1.000 ; \quad \mathrm{TLI}=1.000 ; \quad \mathrm{RMSEA}=0.000)$. We concluded that the path model tested in the present study was fully saturated (i.e., just-identified). The standardized estimates and standard errors of the path analysis model used to investigate the relationships between parental rejection, anger expression, and self-injury are presented in Fig. 1. All the pathways were statistically significant (Fig. 1). Results show that the indirect path from parental rejection via anger-in to self-cutting was significant as the $95 \%$ biascorrected confidence intervals did not include zero (indirect effect $=002$, 95\% CI [0.001, 0.004]). Additionally, the indirect path from parental rejection via anger-out to substance use was significant (indirect effect $=0.002,95 \% \mathrm{CI}$ $[0.001,0.003])$. Further, the indirect effect from parental 
rejection to self-cutting through anger-out (indirect effect $=0.001,95 \%$ CI $[0.000,0.002])$, and the indirect effect from parental rejection to substance use via anger-in were not significant (indirect effect $=0.001,95 \%$ CI $[0.000$, $0.002]$ ), based on the upper and lower limits of the biascorrected confidence intervals, that included zero. Note that the bootstrap confidence intervals were rounded to three decimals.

\section{Discussion}

The main aim of this study was to investigate whether the association between parental rejection and self-cutting and substance (ab)use was mediated by the manner in which anger is expressed. Our results showed that parental rejection increased the likelihood of engaging in both forms of self-injury, and these associations were partially mediated through anger expression. More specifically, parental rejection was related to self-cutting via anger-in, and to substance (ab)use via anger-out.

The prevalence rate of self-cutting (5.3\%) in our sample was in line with previous studies (Rodham et al. 2004). The lifetime prevalence of self-cutting in the present study was somewhat lower than the general NSSI prevalence rate in adolescence (Muehlenkamp et al. 2012). One potential explanation for the lower prevalence of self-cutting may be that, although a two-step assessment (single-item question -interview) has been acknowledged to be a gold standard procedure for NSSI assessment, using a single question has been associated with a lower prevalence rate compared to the use of behavioral checklists (Muehlenkamp et al. 2012). Additionally, the secretive nature of the behavior (Baetens et al. 2011; Martin et al. 2010) may have inflated the occurrence of false negatives (i.e., individuals may have denied engaging in NSSI during the interview, even when they had positively endorsed NSSI in the screening tool). In spite of this shortcoming, the double assessment process adopted in the current study comes with the advantage of the ability to ascertain how individuals interpreted the question presented, and to ensure that the questions regarding NSSI behavior were properly understood by all the participants.

In line with previous research (Bresin and Schoenleber 2015), our findings indicate that the prevalence of NSSI was higher in females as compared to males. However, given the relatively small effect size $(\Phi=0.078)$ associated with the gender differences in the prevalence of NSSI, it can be argued that the gender differences in NSSI is likely to be trivial (Victor et al. 2018). Additionally, the mean age of onset of self-cutting was found to be around 12 years of age, which confirms the findings of previous studies (Gandhi et al. 2018; Plener et al. 2015).
With more than $17 \%$ of the sample reported engaging in this self-injurious behavior, substance use was also found to be a prominent phenomenon among adolescents in our sample. In line with previous studies (Leatherdale and Burkhalter 2012), the prevalence rate of substance use in our sample was higher among males than among females, yet, this difference was accompanied by small effect size $(\Phi=0.11)$. Although small, a possible explanation for this difference could be that males are more prone than females to engage in externalizing behaviors, such as substance use (Rosenfield 2000).

The findings of the present study adds to the existing literature on the association between negative dimensions of parenting and self-harming behaviors (Alati et al. 2014; Bureau et al. 2010; Gandhi et al. 2019) by demonstrating that parental rejection has both a direct and an indirect effect on self-cutting and substance (ab)use through the mediation of anger expression. The indirect effects between parental rejection and self-cutting indicated that anger-in partially mediated the pathway toward NSSI, whereas anger-out partially mediated the pathway toward substance (ab)use. These findings suggest that the manner in which adolescents express their anger may influence whether they will engage in direct or indirect forms of self-injurious behaviors. One possible explanation is that the quality of the relationship with parents has a significant influence on the offsprings' psychological adjustment (Rohner and Britner 2002). In this sense, growing up in a rejecting environment may contribute to a deficiency of self-regulation, triggering anger dysregulation, due to the fact that the adolescent does not develop a sense of effectiveness and worthiness. A possible explanation for the direction of the anger expression is that rejected individuals may experience the desire to attack the self, which they view as unworthy and, then, show a tendency to direct their angry feelings toward themselves (Muehlenkamp et al. 2012). Conversely, the outward expression of anger may result from the desire to avoid feeling overwhelmed by painful affects (i.e., feeling of inadequacy) and direct it outwards.

Our findings are in line with previous studies that have demonstrated that individuals who tend to direct their anger inwardly (anger-in) are more prone to engage in NSSI (Claes et al. 2010; García-Nieto et al. 2015). Moreover, selfdirected anger involves redirecting angry feelings inward against the self, fostering negative consequences aligned with NSSI, such as low self-esteem, self-criticism and selfpunishment (Klonsky 2007).

On the other hand, an externalizing pathway of anger may be a dominant pathway toward substance (ab)use (Evren et al. 2012). Although several studies have examined the role of anger as a risk factor for adolescents' substance use (Nichols et al. 2008; Serafini et al. 2016), only a few studies have explored the role of anger expression in 
predicting substance use. For example, Eftekhari et al. (2004) showed that engaging in alcohol and drug use was more closely related to an externalized expression of anger than to suppression of angry feelings. Consistent with these findings, our study suggests that the dysfunctional externalization of angry feelings may lead to engagement in risky behaviors, such as substance (ab)use (Avci et al. 2017; Baharvand and Mallekshahi 2019; Cautin et al. 2001). Furthermore, according to self-medication model of substance use, anger is an emotional state (i.e., painful affect) that individuals self-medicate through the substance (Khantzian 1997). In conclusion, both NSSI and indirect self-injurious behaviors can be considered as emotionregulation strategies to deal with anger evoked by parental rejection, but directed inwardly or outwardly respectively (Hooley and St. Germain 2014).

\section{Limitation}

Although the study enhances our understanding of the underlying mechanisms between parenting and (in)direct self-injury using a large sample of adolescents, our findings should be considered in the context of some limitations. First, our study only included a non-clinical sample of Southern Italian adolescents, precluding the generalizability of the results to other samples. Second, we assessed both NSSI and indirect forms of self-injurious behaviors using a single-item question. Also, assessing only self-cutting may lead to gender bias, as females are more likely to engage in self-cutting than males (Bresin and Schoenleber 2015). Future research should attempt to replicate these findings using a more comprehensive assessment for NSSI acts, providing NSSI behavior examples within the screening item, and a standardized measure for indirect forms of selfinjury-also assessing frequency. Third, the use of selfreport measures can be biased by recall effects and social desirability. Furthermore, correlations between variables obtained using self-report measures can be overestimated due to shared method variance. Fourth, parenting patterns were assessed based on the adolescent's perception of parenting. To tackle this limitation, future studies should also include parent-reports besides self-report. Fifth, our data was cross-sectional in nature. Thus, we were not able to examine the directionality of the relations between the variables of interest. Future longitudinal studies should focus on the temporal order and interplay between parental rejection, anger expression, and self-injury. Sixth, although the strategies used in the present study to handles missing data (listwise deletion and the WLSMV estimation approach) are known to produce unbiased estimates especially when missingness is limited (Asparouhov and Muthén 2010), further studies should also evaluate the potential consequences of missingness on the model estimates. Lastly, although results provide promising preliminary evidence, direct and indirect forms of NSSI constitute complex behaviors that are triggered by several vulnerability factors. Future studies should also explore inter/intrapersonal, situational and contextual influences to better understand the occurrence of self-harming behaviors among adolescents.

\section{Clinical Implications}

In spite of these limitations, the findings of our study also have some clinical implications, our results show the complex relationship between parental bonding and NSSI and indirect forms of self-injurious behaviors within adolescents, elucidating the role of anger expression as a potential mediator. Moreover, identifying parenting patterns and personal factors that are involved in the initiation and maintenance of self-injury could help clinicians in targeting adolescents at risk for engaging in self-injurious behaviors, and in designing intervention and prevention programs. Research on adolescents' perspectives on selfinjury prevention suggests that family and school may be the most pertinent environments for preventing selfinjurious behaviors (Fortune et al. 2008). From a clinical perspective, our results confirm the bond between family malfunctioning and self-injury. Longitudinal studies have demonstrated that a positive parent-child relationship, characterized by support and cohesion, protects against NSSI and indirect forms of self-injury (Kopak et al. 2012; Taliaferro et al. 2012; Tatnell et al. 2014). Thus, intervention programs for adolescents with self-injury should focus on improving family functioning. As suggested by previous family-based treatments (Glenn et al. 2015), promoting the creation and maintenance of a supportive and functional parent-child relationship might be clinically important in facing self-injurious behaviors during adolescence.

Furthermore, our findings show that dysfunctional anger expression influence both NSSI and indirect forms of selfinjury, supporting the role of self-harm as a mean to deal with negative emotional states. As the age on set of selfinjurious behaviors often occurs during adolescence (Gandhi et al. 2018; Swendsen et al. 2012), specific prevention program within educational settings should be encouraged. The school plays a key role in adolescents development (Brock et al. 2004), and promoting healthy emotion regulation strategies might be an important avenue for preventing self-injury. Specifically, school-based intervention programs may emphasize teaching anger management techniques (Walsh 2006), improving self-esteem and self-awareness, and provide students with alternative ways to express anger in the hope of increasing self-care and reduce self-injury. 
Acknowledgements Open access funding provided by Università degli Studi della Campania Luigi Vanvitelli within the CRUI-CARE Agreement.

Author Contributions P.C. designed the study. S.C. collaborated in study design. A.C. collected the data and performed literature review. A.C., L.C., and A.G. conceptualized the present paper. A.G. and A.C. performed the analyses. A.C. wrote the paper. All authors read and approved the final version of the paper.

\section{Compliance with Ethical Standards}

Conflict of Interest The authors declare that they have no conflict of interest.

Ethical Approval All procedures performed in studies involving human participants were in accordance with the ethical standards of the Department of Psychology, University of Campania "Luigi Vanvitelli", and with the 1964 Helsinki declaration and its later amendments or comparable ethical standards.

Informed Consent Informed consent was obtained from all individual participants included in the study.

Publisher's note Springer Nature remains neutral with regard to jurisdictional claims in published maps and institutional affiliations.

Open Access This article is licensed under a Creative Commons Attribution 4.0 International License, which permits use, sharing, adaptation, distribution and reproduction in any medium or format, as long as you give appropriate credit to the original author(s) and the source, provide a link to the Creative Commons license, and indicate if changes were made. The images or other third party material in this article are included in the article's Creative Commons license, unless indicated otherwise in a credit line to the material. If material is not included in the article's Creative Commons license and your intended use is not permitted by statutory regulation or exceeds the permitted use, you will need to obtain permission directly from the copyright holder. To view a copy of this license, visit http://creativecommons. org/licenses/by/4.0/.

\section{References}

Adalbjarnardottir, S., \& Hafsteinsson, L. G. (2003). Adolescents' perceived parenting styles and their substance use: concurrent and longitudinal analyses. Journal of Research on Adolescence, 11 (4), 401-423. https://doi.org/10.1111/1532-7795.00018.

Alati, R., Baker, P., Betts, K. S., Connor, J. P., Little, K., Sanson, A., \& Olsson, C. A. (2014). The role of parental alcohol use, parental discipline and antisocial behaviour on adolescent drinking trajectories. Drug and Alcohol Dependence, 134(1), 178-184. https://doi.org/10.1016/j.drugalcdep.2013.09.030.

Apter, A., Plutchik, R., \& van Praag, H. M. (1993). Anxiety, impulsivity and depressed mood in relation to suicidal and violent behavior. Acta Psychiatrica Scandinavica. https://doi.org/10. 1111/j.1600-0447.1993.tb03321.x.

Asparouhov, T., \& Muthén, B.O. (2010). Weighted least squares estimation with missing data. MplusTechnical Appendix. http://www.statmodel.com/download/GstrucMissingRevision.pdf.

Avci, D., Tari Elçuk, K., \& Doğan, S. (2017). The prevalence of substance use among adolescents participating in apprenticeship training, relationship between anger level-anger expression and addiction severity. Journal of Psychiatric Nursing. https://doi. org/10.14744/phd.2017.50479.

Baetens, I., Claes, L., Hasking, P., Smits, D., Grietens, H., Onghena, P., \& Martin, G. (2015). The relationship between parental expressed emotions and non-suicidal self-injury: the mediating roles of self-criticism and depression. Journal of Child and Family Studies, 24(2), 491-498. https://doi.org/10.1007/s10826013-9861-8.

Baetens, I., Claes, L., Martin, G., Onghena, P., Grietens, H., Van Leeuwen, K., Pieters, C., Wiersema, J. R., \& Griffith, J. W. (2014). Is nonsuicidal self-injury associated with parenting and family factors. Journal of Early Adolescence, 34(3), 387-405. https://doi.org/10.1177/0272431613494006.

Baetens, I., Claes, L., Muehlenkamp, J., Grietens, H., \& Onghena, P. (2011). Non-suicidal and suicidal self-injurious behavior among flemish adolescents: a web-survey. Archives of Suicide Research, 15(1), 56-67. https://doi.org/10.1080/13811118.2011.540467.

Baetens, I., Claes, L., Onghena, P., Grietens, H., Van Leeuwen, K., Pieters, C., Wiersema, J. R., \& Griffith, J. W. (2014). Nonsuicidal self-injury in adolescence: a longitudinal study of the relationship between NSSI, psychological distress and perceived parenting. Journal of Adolescence, 37(6), 817-826. https://doi. org/10.1016/j.adolescence.2014.05.010.

Baharvand, P., \& Mallekshahi, F. (2019). Relationship between anger and drug addiction potential as factors affecting the health of medical students. Journal of Education and Health Promotion, 8, 157 https://doi.org/10.4103/jehp.jehp_145_19.

Bresin, K., \& Schoenleber, M. (2015). Gender differences in the prevalence of nonsuicidal self-injury: a meta-analysis. Clinical Psychology Review, 38, 55-64. https://doi.org/10.1016/j.cpr. 2015.02.009.

Brock, S.E., Sandoval, J., \& Hart, S. (2004). Suicidal ideation and behaviors. In Bear, G.G.; Minke, K.M., and Thomas, A. (Eds), Children's needs III: development, prevention and intervention (pp. 225-238). Bethesda, MD: National Association of School Psychologists.

Brown, M. W., \& Cudeck, R. (1993). Alternative Ways of Assessing Model Fit. In K. A. Bollen \& J. S. Long (Eds), Testing Structural Equation Models (pp. 136-162). Sage.

Bureau, J. F., Martin, J., Freynet, N., Poirier, A. A., Lafontaine, M. F., \& Cloutier, P. (2010). Perceived dimensions of parenting and non-suicidal self-injury in young adults. Journal of Youth and Adolescence, 39(5), 484-494. https://doi.org/10.1007/s10964009-9470-4.

Cautin, R. L., Overholser, J. C., \& Goetz, P. (2001). Assessment of mode of anger expression in adolescent psychiatric inpatients. Adolescence, 36(141), 163-170.

Cella, S., Iannaccone, M., \& Cotrufo, P. (2014). How perceived parental bonding affects self-concept and drive for thinness: a community-based study. Eating Behaviors, 15(1), 110-115. https://doi.org/10.1016/j.eatbeh.2013.10.024.

Cerutti, R., Presaghi, F., Manca, M., \& Gratz, K. L. (2012). Deliberate self-harm behavior among italian young adults: correlations with clinical and nonclinical dimensions of personality. American Journal of Orthopsychiatry, 82(3), 298-308. https://doi.org/10. 1111/j.1939-0025.2012.01169.x.

Cipriano, A., Cella, S., \& Cotrufo, P. (2017). Nonsuicidal self-injury: a systematic review. Frontiers in Psychology, 8. https://doi.org/10. 3389/fpsyg.2017.01946.

Claes, L., Muehlenkamp, J., Vandereycken, W., Hamelinck, L., Martens, H., \& Claes, S. (2010). Comparison of non-suicidal selfinjurious behavior and suicide attempts in patients admitted to a psychiatric crisis unit. Personality and Individual Differences, 48 (1), 83-87. https://doi.org/10.1016/j.paid.2009.09.001.

Claes, L., Vandereycken, W., \& Vertommen, H. (2003). Eatingdisordered patients with and without self-injurious behaviours: a 
comparison of psychopathological features. European Eating Disorders Review, 11(5), 379-396. https://doi.org/10.1002/erv.510.

Claes, L., Vandereycken, W., \& Vertommen, H. (2004). Family environment of eating disordered patients with and without selfinjurious behaviors. European Psychiatry, 19(8), 494-498. https://doi.org/10.1016/j.eurpsy.2004.09.001.

Claes, L., Vandereycken, W., \& Vertommen, H. (2005). Self-care versus self-harm: piercing, tattooing, and self-injuring in eating disorders. European Eating Disorders Review, 13(1), 11-18. https://doi.org/10.1002/erv.612.

Clark, R., Novak, J. D., \& Dupree, D. (2002). Relationship of perceived parenting practices to anger regulation and coping strategies in African-American adolescents. Journal of Adolescence, 25 (4), 373-384. https://doi.org/10.1006/jado.2002.0482.

Comunian, A. L. (1992). STAXI. State Trait Anger Expression Inventory. Versione e Adattamento Italiano. Manuale. Firenze: Giunti Organizzazioni Speciali.

Comunian, A. L. (2002). A review of Italian research in Rohner's Acceptance-Rejection Theory. In Comunian A. L. \& Gielen U. P. (Eds) It's all about relationships (pp. 71-83). Lengeruch: PABST Science Publishers.

Dickson, D. J., Laursen, B., Valdes, O., \& Stattin, H. (2019). Derisive parenting fosters dysregulated anger in adolescent children and subsequent difficulties with peers. Journal of Youth and Adolescence, 48(8), 1567-1579. https://doi.org/10.1007/s10964-019-01040-z.

Eftekhari, A., Turner, A. P., \& Larimer, M. E. (2004). Anger expression, coping, and substance use in adolescent offenders. Addictive Behaviors, 29(5), 1001-1008. https://doi.org/10.1016/j. addbeh.2004.02.050.

Evren, C., Cinar, O., Evren, B., \& Celik, S. (2012). Self-mutilative behaviors in male substance-dependent inpatients and relationship with anger and aggression: mediator effect of childhood trauma. Comprehensive Psychiatry, 53(3), 252-258. https://doi. org/10.1016/j.comppsych.2011.04.061.

Favazza, A. R. (1996). Bodies under siege: Self-mutilation and body modification in culture and psychiatry. Johns Hopkins University Press.

Fortune, S., Sinclair, J., \& Hawton, K. (2008). Adolescents' views on preventing self-harm. Social Psychiatry and Psychiatric Epidemiology, 43(2), 96-104. https://doi.org/10.1007/s00127-007-0273-1.

Fuqua, D. R., Leonard, E., Masters, M. A., Smith, R. J., Campbell, J. L., \& Fischer, P. C. (1991). A structural analysis of the State-Trait anger expression inventory. Educational and Psychological Measurement, 51(2), 439-446. https://doi.org/10.1177/ 0013164491512018.

Gandhi, A., Luyckx, K., Baetens, I., Kiekens, G., Sleuwaegen, E., Berens, A., Maitra, S., \& Claes, L. (2018). Age of onset of nonsuicidal self-injury in Dutch-speaking adolescents and emerging adults: an event history analysis of pooled data. Comprehensive Psychiatry, 80, 170-178. https://doi.org/10.1016/j.comppsych. 2017.10.007.

Gandhi, A., Luyckx, K., Molenberghs, G., Baetens, I., Goossens, L., Maitra, S., \& Claes, L. (2019). Maternal and peer attachment, identity formation, and non-suicidal self-injury: a longitudinal mediation study. Child and Adolescent Psychiatry and Mental Health, 13(1), 7 https://doi.org/10.1186/s13034-019-0267-2.

García-Nieto, R., Carballo, J. J., Díaz de Neira Hernando, M., de León-Martinez, V., \& Baca-García, E. (2015). Clinical Correlates of Non-Suicidal Self-Injury (NSSI) in an outpatient sample of adolescents. Archives of Suicide Research, 19(2), 218-230. https://doi.org/10.1080/13811118.2014.957447.

Glenn, C. R., Franklin, J. C., \& Nock, M. K. (2015). Evidence-based psychosocial treatments for self-injurious thoughts and behaviors in youth. Journal of Clinical Child \& Adolescent Psychology, 44 (1), 1-29. https://doi.org/10.1080/15374416.2014.945211.
Gratz, K. L. (2001). Measurement of deliberate self-harm: Preliminary data on the deliberate self-harm inventory. Journal of Psychopathology and Behavioral Assessment, 23(4), 253-263. https:// doi.org/10.1023/A:1012779403943.

Guertin, T., Lloyd-Richardson, E., Spirito, A., Donaldson, D., \& Boergers, J. (2001). Self-mutilative behavior in adolescents who attempt suicide by overdose. Journal of the American Academy of Child and Adolescent Psychiatry, 40(9), 1062-1069. https://doi. org/10.1097/00004583-200109000-00015.

Hair, J. F., Anderson, R. E., Tatham, R. L., \& Black, W. C. (1998). Multivariate data analysis. (5th Edition). Prentice Hall.

Hooley, J. M., \& St. Germain, S. A. (2014). Nonsuicidal self-injury, pain, and self-criticism: Does changing self-worth change pain endurance in people who engage in self-injury?. Clinical Psychological Science, 2(3), 297-305. https://doi.org/10.1177/2167702613509372.

Hoyle, R. H. (2012). Handbook of Structural Equation Modeling. Guilford Press.

Hoyle, R. H., \& Panter, A. T. (1995). Writing about structural equation models. In R. H. Hoyle (Ed.), Structural equation modeling: concepts, issues, andapplications. (pp. 158-176). Sage Publications, Inc.

IBM Corp. (2016). IBM SPSS Statistics for Windows, Version 24.0.

ISTAT. (2019a). Popolazione 15 anni e oltre per titolo di studio. http://dati.istat.it/Index.aspx?QueryId=26175.

ISTAT. (2019b). Popolazione e famiglie. https://www.istat.it/it/popola zione-e-famiglie.

Jakobsen, J. C., Gluud, C., Wetterslev, J., \& Winkel, P. (2017). When and how should multiple imputation be used for handling missing data in randomised clinical trials - a practical guide with flowcharts. BMC Medical Research Methodology, 17(1), 162 https:// doi.org/10.1186/s12874-017-0442-1.

Johnson, B., McBride, D., Hopkins, G., \& Pepper, S. (2014). An examination of parent-child relationships and teen substance use: a brief report. Journal of Child and Adolescent Substance Abuse, 23(4), 210-216. https://doi.org/10.1080/1067828X.2013.786926.

Kerr, M.A., \& Schneider, B.H. (2008). Anger expression in children and adolescents: a review of the empirical literature. In Clinical psychology review (Vol. 28, Issue 4, pp. 559-577). https://doi. org/10.1016/j.cpr.2007.08.001.

Khantzian, E. J. (1997). The self-medication hypothesis of substance use disorders: a reconsideration and recent applications. Harvard Review of Psychiatry, 4(5), 231-244. https://doi.org/10.3109/ 10673229709030550.

Kiekens, G., Hasking, P., Claes, L., Mortier, P., Auerbach, R. P., Boyes, M., Cuijpers, P., Demyttenaere, K., Green, J. G., Kessler, R. C., Nock, M. K., \& Bruffaerts, R. (2018). The DSM-5 nonsuicidal self-injury disorder among incoming college students: prevalence and associations with 12-month mental disorders and suicidal thoughts and behaviors. Depression and Anxiety, 35(7), 629-637. https://doi.org/10.1002/da.22754.

Klonsky, E. D. (2007). The functions of deliberate self-injury: a review of the evidence. Clinical Psychology Review, 27(2), 226-239. https://doi.org/10.1016/j.cpr.2006.08.002.

Kopak, A. M., Chen, A. C. C., Haas, S. A., \& Gillmore, M. R. (2012). The importance of family factors to protect against substance use related problems among Mexican heritage and White youth. Drug and Alcohol Dependence, 124(1-2), 34-41. https://doi.org/10. 1016/j.drugalcdep.2011.12.004.

Latina, D., \& Stattin, H. (2016). Toward a re-interpretation of selfharm: a cross-contextual approach. Aggressive Behavior, 42(6), 522-532. https://doi.org/10.1002/ab.21647.

Leatherdale, S. T., \& Burkhalter, R. (2012). The substance use profile of Canadian youth: exploring the prevalence of alcohol, drug and tobacco use by gender and grade. Addictive Behaviors, 37(3), 318-322. https://doi.org/10.1016/j.addbeh.2011.10.007. 
Martin, G., Swannell, S. V., Hazell, P. L., Harrison, J. E., \& Taylor, A. W. (2010). Self-injury in Australia: a community survey. Medical Journal of Australia, 193, 506-510.

Martin, J., Bureau, J. F., Yurkowski, K., Lafontaine, M. F., \& Cloutier, P. (2016). Heterogeneity of relational backgrounds is associated with variation in non-suicidal self-injurious behavior. Journal of Abnormal Child Psychology, 44(3), 511-522. https://doi.org/10.1007/ s10802-015-0048-1.

MIUR. (2017). Le iscrizioni al primo anno delle scuole primarie, secondarie di primo e secondo grado del sistema educativo di istruzione e formazione (p. 20). https://www.miur.gov.it/ documents/20182/0/Le + iscrizioni + al + primo + anno + delle + scuole + primarie $\% 2 \mathrm{C}+$ secondarie $+\mathrm{di}+$ primo $+\mathrm{e}+$ secondo + grado + del + sistema + educativo + di + istruzione $+\mathrm{e}+$ forma zione/68302a9e-3b49-499b-a084-229a1311c134?version=1.0.

Moss, H. B., Chen, C. M., \& Yi, Hye (2014). Early adolescent patterns of alcohol, cigarettes, and marijuana polysubstance use and young adult substance use outcomes in a nationally representative sample. Drug and Alcohol Dependence, 136(1), 51-62. https:// doi.org/10.1016/j.drugalcdep.2013.12.011.

Muehlenkamp, J. J., Claes, L., Havertape, L., \& Plener, P. L. (2012). International prevalence of adolescent non-suicidal self-injury and deliberate self-harm. Child and Adolescent Psychiatry and Mental Health, 6(1), 10 https://doi.org/10.1186/1753-2000-6-10.

Muthén, L. K., \& Muthén, B. O. (2012). Mplus User's Guide. Seventh Edition. Muthén \& Muthén.

Nichols, T. R., Mahadeo, M., Bryant, K., \& Botvin, G. J. (2008). Examining anger as a predictor of drug use among multiethnic middle school students. Journal of School Health, 78(9), 480-486. https://doi.org/10.1111/j.1746-1561.2008.00333.x.

Plener, P. L., Schumacher, T. S., Munz, L. M., \& Groschwitz, R. C. (2015). The longitudinal course of non-suicidal self-injury and deliberate self-harm: a systematic review of the literature. Borderline Personality Disorder and Emotion Dysregulation, 2(1), 2 https://doi.org/10.1186/s40479-014-0024-3.

Quirk, S. W., Wier, D., Martin, S. M., \& Christian, A. (2015). The influence of parental rejection on the development of maladaptive schemas, rumination, and motivations for self-injury. Journal of Psychopathology and Behavioral Assessment, 37(2), 283-295. https://doi.org/10.1007/s10862-014-9453-y.

Richmond-Rakerd, L. S., Slutske, W. S., \& Wood, P. K. (2017). Age of initiation and substance use progression: a multivariate latent growth analysis. Psychology of Addictive Behaviors, 31(6), 664-675. https://doi.org/10.1037/adb0000304.

Rodham, K., Hawton, K., \& Evans, E. (2004). Reasons for deliberate self-harm: comparison of self-poisoners and self-cutters in a community sample of adolescents. Journal of the American Academy of Child and Adolescent Psychiatry, 43(1), 80-87. https://doi.org/10.1097/00004583-200401000-00017.

Rohner, R. P. (2005). Parental Acceptance-Rejection Questionnaire (PARQ): Test Manual. In R. P. Rohner \& A. Khaleque (Eds), Handbook for the Study of Parental Acceptance and Rejection. (pp. 43-106). Rohner Research Publications.

Rohner, R. P. (1986). The warmth dimension: foundations of parental acceptance-rejection theory. New perspectives on family. In journal of marriage and family (Issue 49). Beverly Hills, CA: Sage Publications, Inc.

Rohner, R. P., \& Britner, P. A. (2002). Worldwide mental health correlates of parental acceptance-rejection: review of crosscultural and intracultxiral evidence. Cross-Cultural Research, 36(1), 16-47. https://doi.org/10.1177/106939702129146316.

Rohner, R. P., \& Brothers, S. A. (1999). Perceived parental rejection, psychological maladjustment, and borderline personality disorder. Journal of Emotional Abuse, 1(4), 81-95. https://doi.org/ 10.1300/J135v01n04_05.
Rohner, R. P., Khaleque, A., \& Cournoyer, D. E. (2005). Parental acceptance-rejection: theory, methods, cross-cultural evidence, and implications. Ethos, 33(3), 299-334. https://doi.org/10.1525/ eth.2005.33.3.299.

Rosenfield, S. (2000). Gender and dimensions of the self: implications for internalizing and externalizing behavior. In E. Frank (Ed.) American psychopathological association series. Gender and its effects on psychopathology (pp. 23-36). Washington, DC: American Psychiatric Publishing, Inc.

Rusby, J. C., Light, J. M., Crowley, R., \& Westling, E. (2018). Influence of parent-youth relationship, parental monitoring, and parent substance use on adolescent substance use onset. Journal of Family Psychology, 32(3), 310-320. https://doi.org/10.1037/fa $\mathrm{m} 0000350$.

Schulte, M. T., \& Hser, Y.-I. (2013). Substance use and associated health conditions throughout the lifespan. Public Health Reviews, 35(2), 3 https://doi.org/10.1007/BF03391702.

Senese, V. P., Shinohara, K., Esposito, G., Doi, H., Venuti, P., \& Bornstein, M. H. (2017). Implicit association to infant faces: Genetics, early care experiences, and cultural factors influence caregiving propensities. Behavioural Brain Research, 325, 163-172. https://doi.org/10.1016/j.bbr.2016.09.040.

Serafini, K., Toohey, M. J., Kiluk, B. D., \& Carroll, K. M. (2016). Anger and its association with substance use treatment outcomes in a sample of adolescents. Journal of Child and Adolescent Substance Abuse, 25(5), 391-398. https://doi.org/10.1080/ 1067828X.2015.1049394.

Spielberger, C. D. (1988). Professional manual for the State-Trait Anger Expression Inventory (STAXI): Research edition. Psychological Assessment Resources.

Spielberger, C. D., Reheiser, E. C., \& Sydeman, S. J. (2014). Measuring the experience, expression, and control of anger. In $\mathrm{H}$. Kassinove (Ed.), Anger disorders: definition, diagnosis, and treatment (pp. 49-65). New York: Taylor and Francis. https://doi. org/10.4324/9781315820361.

St. Germain, S. A., \& Hooley, J. M. (2012). Direct and indirect forms of non-suicidal self-injury: evidence for a distinction. Psychiatry Research, 197(1-2), 78-84. https://doi.org/10.1016/j.psychres. 2011.12.050.

Swannell, S. V., Martin, G. E., Page, A., Hasking, P., \& St John, N. J. (2014). Prevalence of nonsuicidal self-injury in nonclinical samples: systematic review, meta-analysis and meta-regression. Suicide and Life-Threatening Behavior, 44(3), 273-303. https:// doi.org/10.1111/sltb.12070.

Swendsen, J., Burstein, M., Case, B., Conway, K. P., Dierker, L., He, J., \& Merikangas, K. R. (2012). Use and abuse of alcohol and illicit drugs in US adolescents: results of the National Comorbidity Survey-Adolescent Supplement. Archives of General Psychiatry, 69 (4), 390-398. https://doi.org/10.1001/archgenpsychiatry.2011.1503.

Taliaferro, L. A., Muehlenkamp, J. J., Borowsky, I. W., McMorris, B. J., \& Kugler, K. C. (2012). Factors distinguishing youth who report self-injurious behavior: a population-based sample. Academic Pediatrics, 12(3), 205-213. https://doi.org/10.1016/j.acap. 2012.01.008.

Tatnell, R., Kelada, L., Hasking, P., \& Martin, G. (2014). Longitudinal analysis of adolescent NSSI: the role of intrapersonal and interpersonal factors. Journal of Abnormal Child Psychology, 42(6), 885-896. https://doi.org/10.1007/s10802-013-9837-6.

Teichman, M., \& Kefir, E. (2000). The effects of perceived parental behaviors, attitudes, and substance-use on adolescent attitudes toward and intent to use psychoactive substances. Journal of Drug Education, 30(2), 193-204. https://doi.org/10.2190/6BPT42KW-9CQY-TPKT.

Victor, S. E., \& Klonsky, E. D. (2018). Understanding the social context of adolescent nonsuicidal self-injury. Journal of Clinical 
Psychology, 74(12), 2107-2116. https://doi.org/10.1002/jclp. 22657.

Victor, S. E., Muehlenkamp, J. J., Hayes, N. A., Lengel, G. J., Styer, D. M., \& Washburn, J. J. (2018). Characterizing gender differences in nonsuicidal self-injury: evidence from a large clinical sample of adolescents and adults. Comprehensive Psychiatry, 82, 53-60. https://doi.org/10.1016/j.comppsych.2018.01.009.

Walsh, B.W. (2006). Treating self-injury: a practical guide. New York: Guilford Press.
World Medical Association. (2013). World medical association declaration of helsinki: Ethical principles for medical research involving human subjects. JAMA-Journal of the American Medical Association, 310(20), 2191-2194. https://doi.org/10. 1001/jama.2013.281053.

Zetterqvist, M. (2017). Nonsuicidal self-injury in adolescents: characterization of the disorder and the issue of distress and impairment. Suicide and Life-Threatening Behavior, 47(3), 321-335. https://doi.org/10.1111/sltb.12283. 